\title{
Phytochemical analysis and anticancer screening of some indigenous plants grown in Saudi Arabia
}

\author{
Sabry A. El-Naggar ${ }^{1,}{ }^{*}$, Mousa O. Germoush², Ibrahim B. Abdel-Farid ${ }^{2,3}$, Hassan A. Elgebaly ${ }^{2}$, \\ Abdelhalim A. Alkazendar ${ }^{4}$. \\ ${ }^{1}$ Zoology Department, Faculty of Science, Tanta University, Tanta 3111, Egypt \\ ${ }^{2}$ Biology Department, College of Science, Jouf University, Kingdom of Saudi Arabia \\ ${ }^{3}$ Botany Department, Faculty of Science, Aswan University, Aswan 81528, Egypt \\ ${ }^{4}$ Department of quality education, Tanta Region of Al-Azhar, Tanta, Egypt.
}

This study was conducted to evaluate the phytochemical analysis, and in vitro anticancer screening of four wild plants grown in the northern region of the Kingdom of Saudi Arabia (KSA), namely: Convolvulus oxyphyllus, Rhazya stricta, Astragalus kahircus and Teucrium polium. Total phenolics content, flavonoids, anthocyanins, saponins, total antioxidant capacity (TAC) and 2,2-diphenyl-1picrylhydrazyl (DPPH) scavenging activity were assessed in their extracts. In vitro anticancer screening of the hydro-alcohol extracts was also assessed using human hepatocellular carcinoma (HepG-2) and breast adenocarcinoma (MCF-7) cell lines. The plant species revealed different metabolomic profiling. $C$. oxyphyllus showed the highest phenolic and flavonoids contents compared to other plant extracts. While, among these plant extracts, $T$. polium showed the highest level of TAC, saponins and anthocyanins contents. C. oxyphyllus showed the highest inhibition concentration $50 \%$ (IC 50$)$ against HepG-2 $(18.8 \mu \mathrm{g} / \mathrm{ml})$ and MCF-7 $(4.1 \mu \mathrm{g} / \mathrm{ml})$. The highperformance liquid chromatography analysis of $C$. oxyphyllus extract revealed the presence of high content of benzoic acid and vanillic acid (phenolics) along with hesperidin (flavonoids). In conclusion, among the screened plants, $C$. oxyphyllus has the most potent anticancer activity against HepG-2 and MCF-7 cell lines in vitro.

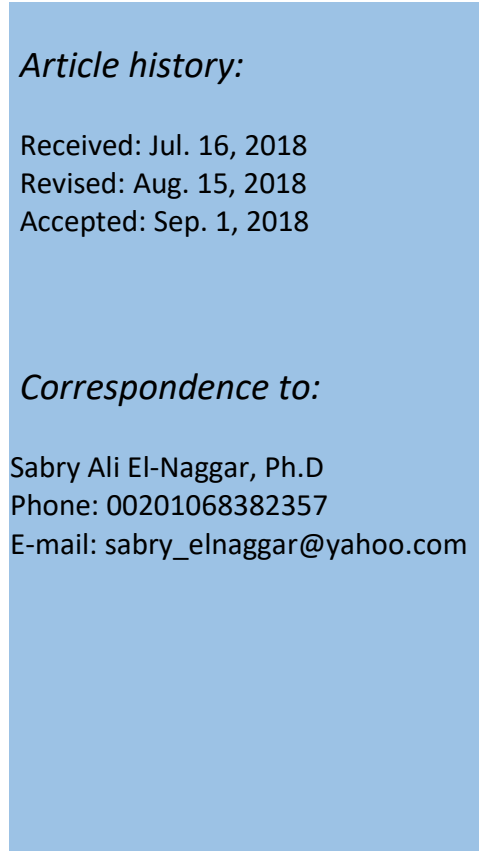

Keywords: Phytochemical; anticancer; plant; extracts; HepG-2; MCF-7; cell lines

\section{INTRODUCTION}

Despite the breakthrough in the treatment of cancer either by surgery, chemotherapy or radiotherapy, the outcomes are still limited. Finding a successful treatment is still a potential challenge. Although, the treatment with chemotherapy is used to halt the growing tumor, the normal cells are also being affected (El-Naggar et al., 2014). Recently, studies have been carried out to find either a new and safe targeted therapy against cancer or to ameliorate the side effects after treatments (El-Naggar et al., 2014; Singh et al., 2018). For instance, some antioxidant agents are considered useful to alleviate oxidative stress, which resulted from chemotherapy. Chemotherapy treatment along with potent antioxidants could be desirable approach to ameliorate toxicity (Kumar and Kuttan, 2005; Sudharsan et al., 2005; Jalali et al., 2012).

Kingdom of Saudi Arabia (KSA) flora is rich with wild medicinal plants commonly used to treat several human diseases (Aboul-Enein et al.,2012; Kuete et al., 2013). The metabolic, antioxidant and anticancer activity of some wild growing medicinal plants in KSA were reported (El-Naggar et al., 2015). The recent studies have directed to screen and evaluate 
the new compounds naturally present especially in the medicinal plants as anticancer agents (Patra et al., 2002; Moustafa et al., 2014). For instance, the methanolic extracts of some plants traditionally used in KSA for the treatment of several diseases were tested for their anticancer activity (Almehdar et al., 2012). By using human breast cancer (MCF-7) and human leukemia (HL-60) tumor cell lines, it has reported that Sesbani agrandflora extract had a potent in vitro anticancer activity (Jeyaraj et al., 2013). The methanol extracts of Gingko biloba, Ipomoea carnea leaves and Lonchocarpus speciosus bark exhibited in vitro anticancer activity against colon cancer cell line (Moustafa et al., 2014). In our recent study, we have found that the hydro-alcoholic extract of Plucaria crispa has a potent antitumor activity in vitro against HepG-2 and MCF-7 cell lines (EINaggar et al., 2015).

Convolvulus oxyphyllus Boiss (Vernacular name: Rukhama) belong to family Convolvulaceae. This plant is ascending, rounded perennial shrublet up to $70 \mathrm{~cm}$ high, bearing numerous straight lateral spiny branchlets (Fahad and Al-Hemaid, 1998). Rhazya stricta Decne is belonging to family Apocynaceae. This plant is a small glaborous erect shrub with a smooth central stem and dense semi-erect branches which grows commonly in the Arabian Peninsula and the Indian subcontinent (Western, 1989). In the traditional medicine, this plant is used to treat diabetes mellitus, inflammation and helminthiasis (Amal et al., 2015; Aisha et al., 2016). Some selected alkaloids and flavonoids isolated from $R$. stricta showed antimicrobial and anticancer properties (Nabih et al., 2012). Mohamed et al. (2009) declared that Astragalus kahiricus DC., a herb highly toxic in livestock with very promising hepatoprotective effect against ethanol-induced liver apoptosis (Allam et al., 2013).

Teucrium polium L. (Lamiaceae) has been used for over 2000 years in traditional medicine. $T$. polium aerial parts are used as antibacterial, anti-inflammatory, antioxidant, antidiabetic and antispasmodic (Sadraei et al., 2001; Yazdanparast et al., 2005; Ljubuncic et al., 2006; Kerbouche et al., 2012; Belmekki et al.,
2013). In addition, this plant is used to lowering blood lipid, induction of vascular relaxation, decreasing of blood pressure and protects against acetaminophen-induced hepatotoxicity (Suleiman et al., 1988; Bello et al., 1988; Shahraki et al., 2007; Kalantari et al., 2013). In this study, we aimed to evaluate the phytochemical properties, antioxidant capacity and in vitro anticancer activity for the hydroalcoholic extract of C. oxyphyllus, R. stricta, $A$. kahiricus and $T$. polium which belonging to different four families, Convolvulaceae, Apocynaceae, Fabaceae and Lamiaceae, respectively.

\section{MATERIALS AND METHODS}

\section{Plant materials collection and plant extracts preparation}

Convolvulus oxyphyllus (shoots), $R$. stricta (leaves), A. kahiricus (shoot system) and $T$. polium (seeds) were collected from desert around Sakaka City, Aljouf region, KSA. The plant materials were identified and authenticated by taxonomist at Camel and Range research center, Sakaka, Aljouf, KSA. The materials were shade dried then ground to powder using electrical mortar. The powder then stored in airtight container until use for further experiments. The shade dried $(50 \mathrm{~g})$ powder of each plant material was filled in a conical flask containing $80 \%$ methanol. After 4 days, the extract was filtered and concentrated in a rotary evaporator at a temperature not exceeding $50^{\circ} \mathrm{C}$.

\section{Spectrophotometrical analysis}

\section{Determination of total phenolics and flavonoids}

Total concentration of phenolics in the extracts was determined using Folin-Ciocalteau reagent with gallic acid as a standard and expressed (mg) as gallic acid equivalents per gram of extract according to Laplaze et al. (1999). Total flavonoids content was determined using the aluminum chloride colorimetric method with quercetin as a standard and expressed (mg) as quercetin equivalent per gram of extract according to Zhishen et al. (1999). 


\section{Determination of saponins and anthocyanins content}

Saponins content was determined using vanillin solution according to Ebrahimzadeh and Niknam, (1998) and expressed (mg) as saponins equivalents per gram of extract. The anthocyanins content of the plant extracts was determined according to the modified method of Padmavati et al. (1997). One hundred mg of plant materials was dissolved in acidified methanol in well closed tubes covered with aluminum foils and incubated at refrigerator for $24 \mathrm{~h}$. The absorbance was read at $530 \mathrm{~nm}$ and $657 \mathrm{~nm}$. The concentration was calculated using the following equation: anthocyanin concentration $(\mu \mathrm{mol} / \mathrm{g})=([\mathrm{A} 530-0.33 \times$ A657]/31.6) X (volume [ml]/weight [g]).

\section{Determination of total antioxidant capacity and 2,2-diphenyl-1picrylhydrazyl (DPPH) assays}

Total antioxidant capacity (TAC) was determined using phospho-molybednum method according to Prieto et al. (1999). TAC was expressed as ascorbic acid equivalent. Free radical scavenging activity of the sample extracts was determined spectrophotometrically using the method of Blois (1958), after obtaining crude extracts from the samples through evaporation of the solvent. The scavenging activity on the DPPH radical was expressed as inhibition percentage using the following equation: \% radical scavenging activity $=(A c-A s / A c) \times 100$, where $A c=$ Absorbance of negative control at $517 \mathrm{~nm}$ and $A s=$ Absorbance of sample at $517 \mathrm{~nm}$ (Wang and Mazza, 2002).

\section{Cancer cell lines}

Human breast adenocarcinoma (MCF-7) and hepatocellular carcinoma (HepG-2) were obtained from Vacsira, Egypt. Cells were cultured in RPMI-1640 medium, supplemented with $10 \%$ fetal bovine serum (FBS), $2 \mathrm{~mL}$ glutamine, containing 100 units $/ \mathrm{ml}$ penicillin, 100 units $/ \mathrm{ml}$ streptomycin at $37^{\circ} \mathrm{C} / 5 \% \mathrm{CO} 2$

\section{Plant extracts and doxorubicin preparation for in vitro use}

Different concentrations of each methanolic extract were prepared at $6.25,12.5,25,50$, and $100 \mu \mathrm{g} / \mathrm{ml}$ dissolved in DMSO (1\%). Doxorubicin (Dox.) was also prepared at the same concentrations as mentioned above under the same conditions and used as positive control.

\section{Determination of inhibition concentration $50 \%$ (IC50) for extracts using sulforhodamine $B$ (SRB) colorimetric assay}

The cytotoxicity of the plants extracts was tested against MCF-7, HepG-2 cell lines by SRB assay according to Vichai and Kirtikara, (2006). Briefly, the adherent cells were collected after trypsinization using $0.25 \%$ Trypsin-EDTA then washed twice and plated in 96-well plates at 1000-2000 cells/well. Cells were exposed to different extracts for $72 \mathrm{~h}$ and subsequently fixed with $10 \%$ trichloroacetic acid (TCA) for $1 \mathrm{~h}$ at 4 으. After several washings using distilled water, cells were exposed to $0.4 \%$ SRB solution (dissolved in 1\% glacial acetic acid) for $10 \mathrm{~min}$ in dark place. $1 \%$ glacial acetic acid was used to wash the plates several times. After drying overnight, Tris-HClwas used to dissolve the SRB-stained cells and color intensity was measured at $570 \mathrm{~nm}$ with micro plate reader. The results were linear over a 20-fold range of cell numbers and the sensitivity is comparable to those of fluorometric methods.

\section{Identification and quantification of phenolics and flavonoids by HPLC}

Analyses were carried out using a Perkin-Elmer HPLC system (USA) equipped with a binary LC250 gradient pump and LC-290 UV/Vis detector. Samples were separated on C18 Hypersil ODS column $(100 \times 4.6 \mathrm{~mm})$ with $5 \mu \mathrm{m}$ particle size according to Ruiz et al. (2011). The mobile phase consisted of eluent $A, 3.0 \%$ acetic acid in water $(\mathrm{v} / \mathrm{v})$ and eluent $\mathrm{B}$, methanol. The elution gradient was: at $0 \mathrm{~min}, 0 \% \mathrm{~B}$; at $10 \mathrm{~min} 10 \% \mathrm{~B}$; at $40 \mathrm{~min}, 70 \% \mathrm{~B}$; at $50 \mathrm{~min} 0 \% \mathrm{~B}$ at a constant flow rate of $1 \mathrm{ml} \mathrm{min}{ }^{-1}$. Phenolic compounds were monitored by absorption at 280 and 330 $\mathrm{nm}$. All measurements were performed in triplicates. Individual phenolic compounds of each sample were identified by comparing their relative retention time with those of the standard mixture chromatogram. A mixture of 
17 standard (HPLC grade) phenolic compounds were used for the HPLC analysis. The concentration of each identified compound was calculated by comparing its peak area with that of the comparable standard, then converted to $\mathrm{mg}$ phenolic $\mathrm{g}^{-1}$ dried extract. All standards and solvents were HPLC spectral grade.

\section{Statistical analysis}

One-way analysis of variance (ANOVA) through the statistical computer programme MINITAB (version 12.21) was used to test the significance of quantitative data of phytochemical analysis and antitumor activity. For SRB assays, the sigma plot program was used to analyze the generated data

\section{RESULTS}

Metabolomic profiling and antioxidant capacity of plant extracts were determined. The potentiality of anticarcinongenic activity of the plant extracts depends on the metabolomic profiling of that extract. Metabolomic profiling of $C$. oxyphyllus, $R$. stricta, A. kahircus and $T$. polium was detected through the determination of the total phenolics, flavonoids, anthocyanins, saponins, TAC and DPPH radical scavenging activity. The results showed that each plant extract has its specific metabolomic profiling.

C. oxyphyllus extract showed the highest phenolics and flavonoids content

As shown in Figure $1 \mathrm{~A}$, the phenolics content showed specific pattern of variation among different species. The highest content of phenolics content was found in C. oxyphyllus (MPT-55). Significant difference was also detected between the content of phenolics in C. oxyphyllus (MPT-55) and the other three plants extracts, R. stricta (MPT-53), A. kahiricus (MPT-5) and T. polium (MPT-16).

Similar to the phenolics profile, $C$. oxyphyllus (MPT-55) showed highest content of flavonoids as shown in Figure 1B. Both of $R$. stricta (MPT53), A. kahiricus (MPT-5) and T. polium (MPT16) showed moderate flavonoids contents. Significant difference was also observed between the content of flavonoids in $C$. oxyphyllus and the other three plants extracts,
R. stricta (MPT-53), A. kahiricus (MPT-5) and T. polium (MPT-16). T. polium showed the highest level of saponins and anthocyanins contents
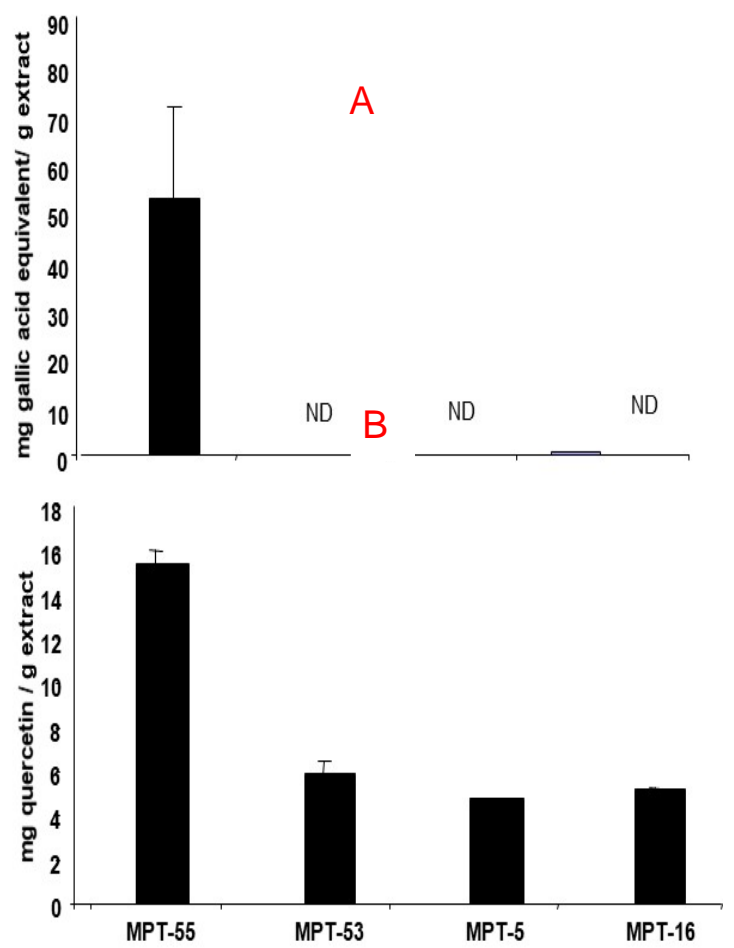

Fig.1. Total phenolics (A) and flavonoids (B) concentrations in the different methanolic plant extracts. MPT-55 (C. oxyphyllus, Shoot system), MPT-53 (R.stricta, Leaves), MPT-5 (A.kahircus, Shoot system), MPT-16 (T. polium, seeds).

Among the species under the study, T. polium (MPT-16) showed the highest saponins content. As shown in Figure 2A, R. stricta (MPT-53), A. kahiricus (MPT-5) and T. polium (MPT-16) showed low level of saponins content. Similar to the saponins profile, $T$. polium (MPT-16) showed the highest content of anthocyanins (Figure 2B). Both of $C$. oxyphyllus (MPT-55), R. stricta (MPT 53) and $A$. kahiricus (MPT-5) showed moderate levels of anthocyanins contents (Figure 2B).

\section{TAC and DPPH radical scavenging activity}

Regarding to total antioxidant capacity (TAC), T. polium (MPT-16) showed the highest TAC among other extracts. C. oxyphyllus (MPT-55), R. stricta (MPT-53) and A. kahiricus (MPT-5) showed moderate TAC activities (Figure 3 ). 


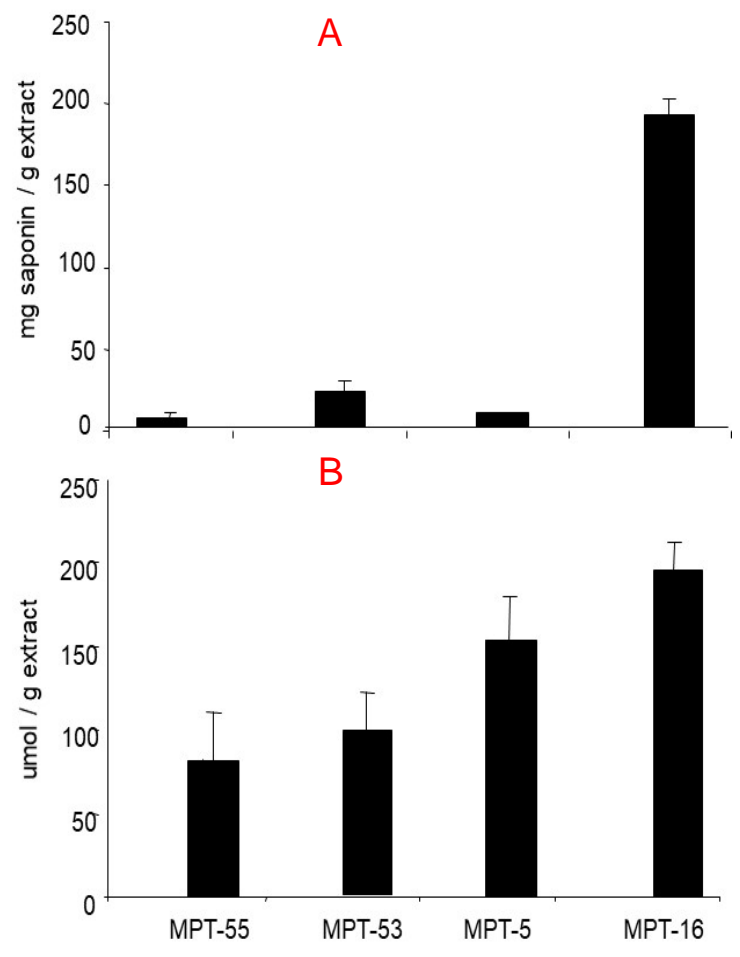

Fig. 2. Saponins (A) and anthocyanins (B) concentrations in the different methanolic plant extracts. Labelling is the same as Fig. 1.

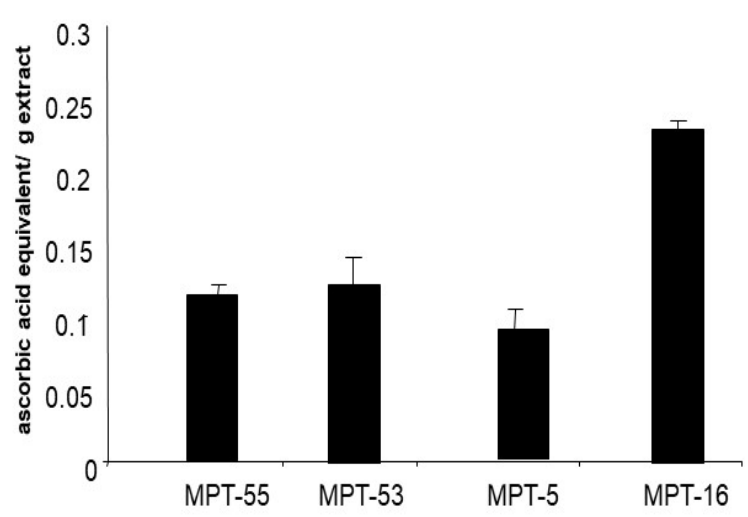

Fig. 3. Total antioxidant capacity (TAC) in the different methanolic plant extracts. MPT-55. Labelling is the same as Fig. 1 and 2.

DPPH radical scavenging activity of $C$. oxyphyllus and T. polium showed the highest percentage registering $89.4 \%$ and $34.4 \%$, respectively (Table 1). The inhibition concentration $\left(\mathrm{IC}_{50}\right)$ of $C$. oxyphyllus and $T$. polium extracts were 55.9 and $145 \mu \mathrm{g} / \mathrm{ml}$, respectively (Table 1 ). DPPH radical scavenging activity was not detected on $R$. stricta (MPT53) and $A$. kahiricus (MPT-5) extracts.
Table 1. DPPH radical scavenging activity and the inhibition concentration $\left(\mathrm{IC}_{50}\right)$ of the selected plant extracts under the study.

\begin{tabular}{c|c|c|c}
\hline Plant species & $\begin{array}{c}\text { Code } \\
\text { no. }\end{array}$ & DPPH \% & $\begin{array}{c}\text { IC }_{50} \\
(\mu \mathrm{g} / \mathrm{ml})\end{array}$ \\
\hline C. oxyphyllus & MPT-55 & $89.4 \pm 1.9$ & 55.9 \\
\hline R. stricta & MPT-53 & ND & ND \\
\hdashline A. kahircus & MPT-5 & ND & ND \\
\hdashline T. polium & MPT-16 & $34.4 \pm 3.9$ & 145 \\
\hline
\end{tabular}

The inhibition concentration 50\% (IC50) of different extracts on HepG-2 and MCF-7 cell lines in vitro

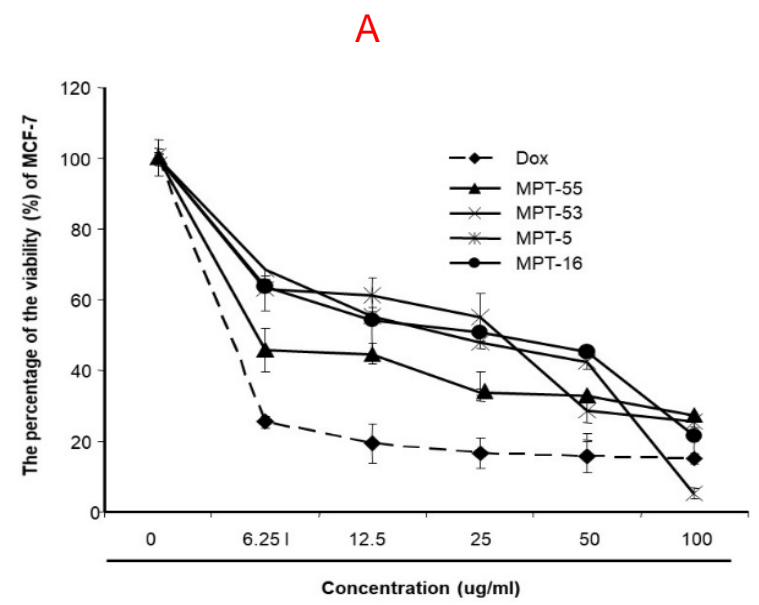

B

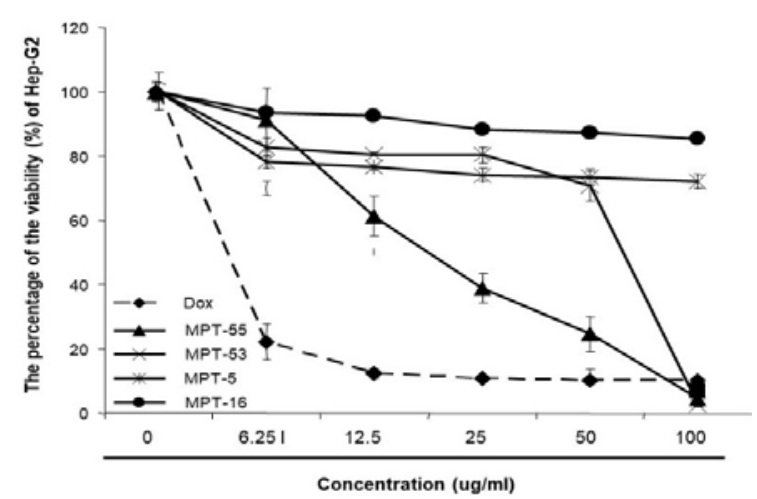

Figure 4. Effect of plants extracts on the viability on MCF-7 and Hep-G2 cell lines. Using 96-well plates, the MCF-7 (A) or Hep-G2 (B) cell lines was cultured in complete RPMI and treated with different concentrations of the methanolic plant extracts (showed in Table 1). The tumor cell line then incubated for $72 \mathrm{hr}$. the chemotherapeutic drug, doxorubicin (Dox.) was used as a positive control under the same concentrations and conditions. The treated cells were used to determine the viability of the tumor cells after $72 \mathrm{hr}$ by MTT assay. The experiment repeated twice 
The HepG-2 line was used to assess the $\mathrm{IC}_{50}$ in vitro after $72 \mathrm{hr}$ post treatments. The results showed that compared to the positive control Dox. $\left(\mathrm{IC}_{50} 3.07 \mathrm{ug} / \mathrm{ml}\right)$, the $\mathrm{IC}_{50}$ of $C$. oxyphyllus (MPT-55), R. stricta (MPT-53), A. kahiricus (MPT-5) and T. polium (MPT-16) were 18.8, 58.4, 119.5 and $143.1 \mathrm{ug} / \mathrm{ml}$, respectively (Table 2 and Figure 4A). The inhibition concentration $50 \%\left(\mathrm{IC}_{50}\right)$ of the previous plant extracts was also determined using MCF-7 cell lines in vitro after $72 \mathrm{hr}$ post treatments. The results showed that compared with the Dox. $\left(\mathrm{IC}_{50} 2.41 \mathrm{\mu g} / \mathrm{ml}\right)$, the IC50 of $C$. oxyphyllus (MPT-55), R. stricta (MPT-53), A. kahiricus (MPT-5) and T. polium (MPT-16) were 4.1, 18.6, 20.4 and $20.2 \mu \mathrm{g} / \mathrm{ml}$, respectively. (Table 2 and Figure 4B).

Table 2. The inhibition concentration $50 \% I_{50}$ ) of some different plant extracts versus the conventional chemotherapeutic drug, doxorubicin on Hep-G2 and MCF-7 cell lines in vitro after $72 \mathrm{hr}$ post treatments

\begin{tabular}{|c|c|c|c|c|}
\hline $\begin{array}{l}\text { Plant } \\
\quad \text { species }\end{array}$ & $\begin{array}{l}\text { Code } \\
\text { no. }\end{array}$ & $\begin{array}{l}\text { Extracted } \\
\text { from }\end{array}$ & $\begin{array}{c}I_{50} \text { (Hep-G2) } \\
I_{50}(\text { Hep-G2) } \\
(\mu \mathrm{g} / \mathrm{ml})\end{array}$ & $\begin{array}{l}\mathrm{IC}_{50} \\
(\mathrm{MCF}-7) \\
(\mu \mathrm{g} / \mathrm{ml})\end{array}$ \\
\hline $\begin{array}{l}\text { C. } \\
\text { Coxyphyllus }\end{array}$ & MPT-55 & Shoot & 18.8 & 4.1 \\
\hline R. stricta & MPT-53 & Leaves- & 58.4 & 18.6 \\
\hline A. kahircus & MPT-5 & Shoot & 119.5 & 20.4 \\
\hline T. polium & MPT-16 & Seeds & 143.1 & 20.2 \\
\hline \multicolumn{3}{|c|}{ Doxorubicin } & 3.07 & 2.41 \\
\hline
\end{tabular}

Table 3 A. Assignment of the HPLC peaks of phenolics in $\mathrm{MeOH}$ extract from $C$. oxyphyllus shoot system

\begin{tabular}{c|l|c}
\hline No. & \multicolumn{1}{|c|}{ Phenolic } & Conc. $\mu \mathrm{g} / \mathrm{ml}$ \\
\hline 1. & Chlorogenic acid & 79.14 \\
\hline 2. & e-vanillic acid & 118.19 \\
\hline 3. & Catechol & 76.55 \\
\hline 4. & Saylcilic acid & 25.89 \\
\hline 5. & Pyrogallol & 38.37 \\
\hline 6. & Benzoic & 244.47 \\
\hline 7. & P-OH-benzoic & 31.17 \\
\hline 8. & Cinnamic & 12.15 \\
\hline 9. & Ellagic & 15.33 \\
\hline 10. & 3-OH- Tyrosol & 16.20 \\
\hline 11. & Epicatechein & 13.44 \\
\hline
\end{tabular}

Table 3 B. Assignment of the HPLC peaks of flavonoids in $\mathrm{MeOH}$ extract from $C$. oxyphyllus shoot system.

\begin{tabular}{c|l|l}
\hline Conc. $\mu \mathrm{g} / \mathrm{ml}$ & \multicolumn{1}{|c|}{ Flavonoids } & \multicolumn{2}{c}{ No. } \\
\hline 1717.32 & Hesperidin & 1 \\
\hline 32.64 & Rutin & 2 \\
\hline 77.32 & Narginin & 3 \\
\hline 21.38 & Rosmarinic acid & 4 \\
\hline-- & Quercetin & 5 \\
\hline-- & Kaempferol & 6 \\
\hline 5.09 & Hispertin & 7 \\
\hline 1.44 & Aspegenin & 8 \\
\hline 3.06 & Narengenin & 9 \\
\hline 0.47 & 7-OH flavone & 18 \\
\hline 1.07 & Quercetrin & 11 \\
\hline
\end{tabular}

\section{HPLC analysis for phenolic of $\boldsymbol{C}$. oxyphyllus}

Based on the phytochemical analysis and anticancer activities of the tested plants extract, the $C$. oxyphyllus methanolic extract (MPT-55), showed the highest cytotoxic effect against HepG-2 and MCF-7 cell lines in vitro. To this end, we further analyzed this extract by HPLC to determine the major phenolics and flavonoids compounds. The results showed that the major phenolic compounds were benzoic acid and e-vanillic acid (Table $3 \mathrm{~A}$ and Figure 5A). Moreover, hesperidin was identified as major flavonoids content in the extract (Table 3B and Figure 5B).

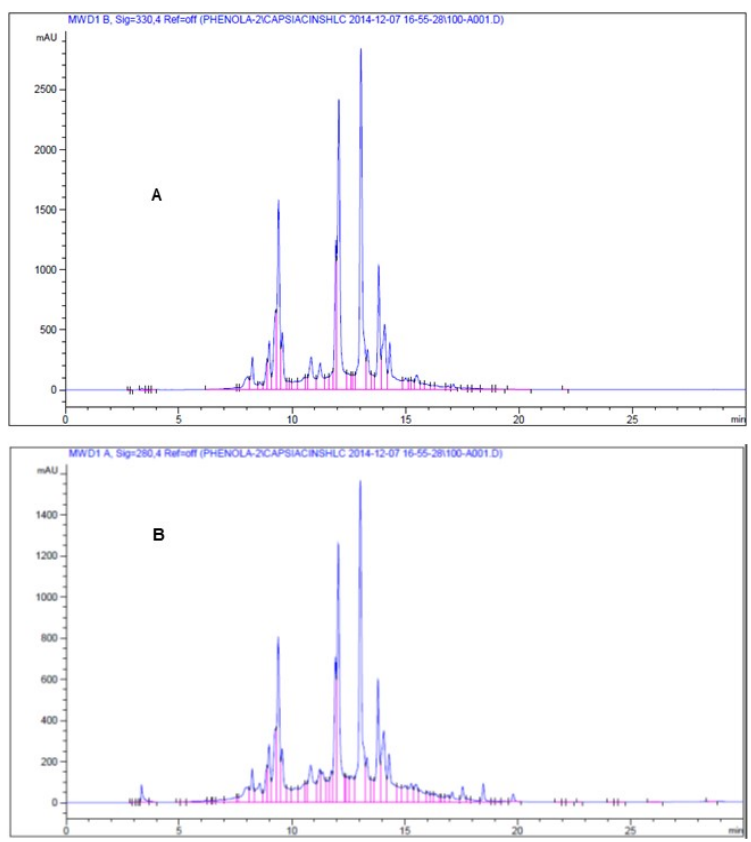

Fig. 5. The phenolics (A) and flavonoids compounds (B) in methanolic extract of $C$. oxyphyllus by HPLC analysis 


\section{DISCUSSION}

For cancer patients, chemotherapy is recommended for the treatment; however, it has severe side effects on different organs upon its application. So that finding new treatment approaches to fight against cancer are ultimately needed. One of these approaches is to screen the medicinal plants to find new natural compounds that might replace the conventional chemotherapy or at least mitigate its side effects (Kumar and Kuttan, 2005; Sudharsan et al., 2005; Ghasemzadeh et al., 2015). In this study, we evaluated the phytochemical properties, antioxidant capacity and in vitro anticancer activity of $C$. oxyphyllus, $R$. stricta, A. kahircus and $T$. polium. The phytochemical screening showed that $C$. oxyphyllus has the highest content of phenolics and flavonoids contents among the tested extracts, while the $T$. polium showed the highest saponins and anthocyanins contents. This finding is in agreement with previous reports which showed that there is a significant positive correlation between various secondary metabolites content such as phenolics, flavonoids, saponins and anthocyanins with the total antioxidant capacity (Basar et al., 2013; Abdel-Farid et al., 2014). In our previous work, we found that TAC was to be positively correlated with saponins and flavonoids content (Abdel-Farid et al., 2014). In this study, we found that the four tested plant extracts have strong anticancer activity against MCF-7 cell line in vitro, however, only the methanolic extract of $C$. oxyphyllus showed the most potent anticancer activity against HepG-2 cell line in vitro. The strong anticarcinogenic activities against HepG2 and MCF-7 cell lines may be attributed to the high content of some secondary metabolites such as phenolics, flavonoids and saponins in these extracts. Consistent with our findings, Elmasri et al. (2015) reported that there were three saponins of $T$. polium completely inhibited the growth of a breast and colon cancer cell line in vitro. In other study, Mosadegh et al. (2002) reported that the aerial parts of $T$. polium have saponins and flavonoides with antibacterial but not antifungal effect. According to these studies, saponins in $T$. polium are biologically active compounds. The methanolic extract of $T$. polium was found to increase the cytotoxic and apoptotic effects of the different chemotherapeutic drugs such as vincristine, vinblastine and doxorubicin against a panel of cancerous cell lines. Furthermore, T. polium extract showed inhibition of cell proliferation and induced cell cycle arrest of human prostate cancer cells (Rajabalian, 2008; Kandouz et al., 2010), protective effect on hepatotoxicity (Forouzandeh et al., 2013) and anticancer activity on hepatocellular carcinogenic (Movahedi et al., 2014). The leaves, flowers and fruits of $R$. stricta are also used to treat cancer (Khan, 2007). The ethanol extract of $A$. kahiricus roots showed hepatoprotective potentiality against ethanol-induced liver apoptosis (Allam et al., 2013). A novel anticancer effect has been found of Astragalus saponins (Auyeung et al., 2009). Consistent with these findings, it could explain the potent activity of $T$. polium, $R$. stricta and $A$. kahiricus extracts as cytotoxic agents against MCF-7 cell lines in vitro.

\section{Conclusion}

C. oxyphyllus (MPT-55) showed the most potent cytotoxic effect against HepG-2 and MCF-7 cell lines while, T. polium, R. stricta and A. kahiricus showed potential cytotoxic effect against MCF-7 cell line in vitro.

\section{Acknowledgements}

This article was supported by Jouf University, project No. 34/218. We would like to acknowledge the researchers in the Camel and Range Research Center, Sakaka City, Aljouf Region, KSA, for their assistance in identifying the plant species during this study.

\section{REFERENCES}

Abdel-Farid IB, Sheded MG and Mohamed EA (2014) Metabolomic profiling and antioxidant activity of some. Acacia species. Saudi J Biol Sci; 21: 400-408.

Aboul-Enein AM, AbuEl-Ela F, Shalaby EA and ElShemy HA (2012) Traditional medicinal plants research in Egypt: Studies of antioxidant and anticancer activities. J Med Plants Res; 6: 689703.

Aisha A, Mariya A, Zainab A and Dhanalekshmi U (2016) A review on medicinal plant Rhazya stricta Decne. Adv Pharm J; 5: 119-125. 
Allam RM, Selim DA, Ghoneim Al, Radwan MM, Nofal SM, Khalifa AE, Sharaf OA, Toaima SM, Asaad AM and El-Sebakhy NA (2013) Hepatoprotective effects of Astragalus kahiricus root extract against ethanol-induced liver apoptosis in rats. Chin J Nat Med; 11(4): 354-61.

Almehdar $\mathrm{H}$, Abdallah HM, Osman AM and AbdelSattar EA (2012) In vitro cytotoxic screening of selected Saudi medicinal plants. J Nat Med; 66: 406-412.

Amal A, Almostady Mohammed H, Mutwakil MZaki, ElAssouli, Mohamed M, Ahmed Sufian M and El Assouli (2015) Genotoxicity and antigenotoxicity activites of Rhazya stricta and Zingiber officinale Single and in Combination. Am-Eurasian J Agric Environ Sci; 15: 13921401.

Auyeung KK1, Cho CH and Ko JK (2009) A novel anticancer effect of Astragalus saponins: Transcriptional activation of NSAID-activated gene. Int J Cancer; 125(5): 1082-1091.

Basar MH, Hossain SJ, Sadhu SK and Rahman MH (2013) A comparative study of antioxidant potential of commonly used antidiabetic plants in Bangladesh. Orient. Pharm Exp Med; 13: 21-28.

Bello R, Calatayud S, Moreno L, Beltrán B, PrimoYúfera $E$ and Esplugues J (1998) Effects on arterial blood pressure of the methanol extracts from different Teucrium species. Phytother Res; 11: 330-1.

Belmekki N, Bendimerad N, Bekhechi C and Fernandez $X$ (2013) Chemical analysis and antimicrobial activity of Teucrium polium L essential oil from Western Algeria. J Med Plants Res; 7: 897-902.

Blois MS (1958) Antioxidant determinations by the use of a stable free radical. Nature; 181: 11991200.

Ebrahimzadeh H and Niknam V (1998) A revised spectrophotometric method for determination of triterpenoid saponins. Indian Drugs; 35: 379-381.

Elmasri Wael A, Mohamed-Elamir F Hegazy, YehiaMechref and Paul W Paré (2015) Cytotoxic saponin poliusaposide from Teucrium polium. RSC Adv; 5: 27126-27133.

El-Naggar SA, Alm-Eldeen AA, Germoush MO, Elboray KF and Elgebaly HA (2014) Ameliorative effect of propolis against cyclophosphamide induced toxicity in mice. Pharm Biol; 53: 235241.

El-Naggar SA, Abdel-Farid, IB, Elgebaly, HA and Germoush, MO (2015) Metabolomic profiling, antioxidant capacity and in vitro anticancer activity of some compositae plants growing in
Saudi Arabia. Afr J Pharm Pharmacol; 9(30): 764-774.

Fahad MA and Al-Hemaid FM (1998). Preliminary Study on the Vegetation of the Rawdhat Umm Hazm, Saudi Arabia. Saudi J Biol Sci; 5(1): 3-8.

Forouzandeh H, Azemi ME, Rashidi I, Goudarzi M and Kalantari $H$ (2013). Study of the Protective Effect of Teucrium polium L. Extract on Acetaminophen-Induced Hepatotoxicity in Mice. Iran J Pharm Res; 12(1): 123-129.

Ghasemzadeh A, Jaafar HZ and Rahmat A (2015) Phytochemical constituents and biological activities of different extracts of Strobilanthes crispus (L) Bremek leaves grown in different locations of Malaysia. BMC Complement Altern Med; 15: 422.

Jalali AS, Hasanzadeh S and Malekinejad H (2012) Achillea millefoliumin florescence aqueous extract ameliorates cyclophosphamideinduced toxicity in rat testis:stereological evidences. Chinese J Nat Med; 10: 247-254

Jeyaraj M1, Sathishkumar G, Sivanandhan G, MubarakAli D, Rajesh M, Arun R, Kapildev G, Manickavasagam M, Thajuddin N, Premkumar K and Ganapathi A (2013) Biogenic silver nanoparticles for cancer treatment: an experimental report. Colloids Surf B Biointerfaces; 1(106): 86-92.

Kalantari H, Forouzandeh H, Azemime, Rashidi I and Goudarzi M (2013) Study of the protective effect of Teucrium polium $\mathrm{L}$ extract on acetaminophen-induced hepatotoxicity in mice. Iran J Pharm Res; 12(1): 123-129.

Kandouz M, Alachkar A, Zhang L, Dekhil H, Chehna F, Yasmeen A and Al Moustafa A (2010). E. Teucrium polium plant extract inhibits cell invasion and motility of human prostate cancer cells via the restoration of the Ecadherin/ catenin complex. J Ethnopharmacol; 129: 410-415.

Kerbouche L, Hazzit M, Ferhat MA, Baaliouamer A and Miguel MG (2012) Biological activities of essential oils and ethanol extracts of Teucrium polium subsp. Capitatum (L) Briq and Origanumfloribundum Munby J Essent Oil Bearing Plants; 18 (5): 1197-1208.

Khan S K and Pak GM (2007) In vitro antifungal activity of Rhazya stricta. J Pharm Sci; 20(4): 274-279.

Kuete V, Wiench B, Alsaid M, Alyahya M, Fankam A and Shahat A (2013). Cytotoxicity, mode of action and antibacterial activities of selected Saudi Arabian medicinal plants. BMC Complement Altern Med; 13: 354.

Kumar KB and Kuttan RC (2005) hemoprotective activity of an extract of Phyllanthus amarus 
against cyclophosphamide induced toxicity in mice. Phytomedicine; 12(6-7): 494-500.

Laplaze L, Gherbi H, Frutz T, Pawlowski K, Franche C, Macheix J, Auguy F, Bogusz D and Duhoux E (1999). Flavan-Containing Cells Delimit Frankia-Infected Compartments in Casuarina glauca Nodules. Plant Physiol; 121(1): 113122.

Ljubuncic P, Dakwar S, Portnaya I, Cogan U, Azaizeh $\mathrm{H}$ and Bomzon A (2006) Aqueous extracts of Teucrium polium possess remarkable antioxidant activity in vitro. Evid-Based Complement Altern Med; 3: 329-38.

Mohamed, II, Hassan HE, Ahmed AA and Bahaa SM (2009) Alkaloids of Astragalus kahiricus DC plant roots. Bull Fac Agric Cairo Univ; 60: 366370.

Mosadegh M, Dehmoubed SA, Nasiri P, Esmaeili S and Naghibi F (2002) The study of phytochemical, antifungal and antibacterial effects of Teucrium polium and Cichourium intybus. Sci J Kurdistan Univ Med Sci; 7(1): 1-6.

Moustafa SA, Menshawi BM, Wassel GM, Mahmoud K and Mounier MM (2014) Screening of some plants in Egypt for their cytotoxicity against four human cancer cell lines. Int J PharmTech Res; 6(3): 1074-1084.

Movahedi A, Basir R, Rahmat A, Charaffedine M and Othman F (2014). Remarkable anticancer activity of Teucrium polium on hepatocellular carcinogenic rats. Evid- Based Complement Altern Med 1-9.

Nabih A. Baeshen, Ayman I. Elkady, Osama A. Abuzinadah and Mohammed H. Mutwakil. (2012) Potential anticancer activity of the medicinal herb, Rhazya stricta, against human breast cancer. Afr J Biotechnol; 11(37): 89608972.

Padmavati M, Sakthivel N, Thara TV and Reddy AR (1997) Differential sensitivity of rice pathogens to growth inhibition by flavonoids. Phytochemistry; 46: 449-502.

Patra K, Bose S, Sarkar S, Rakshit J, Jana S and Mukherjee A (2002) Amelioration of cyclophosphamide induced myelosuppression and oxidative stress by cinnamic acid. ChemBiol Interact; 5: 231-239.

Prieto P, Pineda M and Aguilar M (1999) Spectrophotometric quantitation of antioxidant capacity through the formation of a phosphomolybdenum complex: specific application to the determination of vitamine $E$ Anal. Biochem 269: 337-341.

Rajabalian S (2008). Methanolic extract of Teucrium polium L. potentiates the cytotoxic and apoptotic effects of anticancer drugs of vincristine, vinblastine and doxorubicin against a panel of cancerous cell lines. ExpOncol; 30(2): 133-138.

Ruiz J, Ascasio JA, Rodriguez R, Morales D and Aguilar CN (2011). Phytochemical screening of extracts from some Mexican plants used in traditional medicine. J Med Plant Res; 5(13): 2791-2797.

Sadraei H, Hajhashemi V, Ghannad A and Mohseni $M$ (2001) Antispasmodic effect of aerial part of Teucrium polium L. essential oil on rat isolated ileum in vitro. Med J Islamic Rep Iran; 14: 3558.

Shahraki MR, Arab MR, Mirimokaddam E and Palan MJ (2007) The effect of Teucrium polium (Calpoureh) on liver function, serum lipids and glucose in diabetic male rats. Iran Biomed J; 11: 65-68.

Singh K, Bhori M, ArfatKasu Y, Bhat G and Marar T (2018). Antioxidants as precision weapons in war against cancer chemotherapy induced toxicity - Exploring the armoury of obscurity. Saudi Pharm J; 26(2): 177-190.

Sudharsan PT, Mythili Y, Selvakumar $E$ and Varalakshmi P (2005) Cardioprotective effect of pentacyclictriterpene, lupeol and its ester on cyclophosphamide-induced oxidative stress. Hum ExpToxicol; 24(6): 313-8.

Suleiman MS, Abdul-Ghani AS, Al-Khalil S and Amir R. (1988). Effect of Teucriumpolium boiled leaf extract on intestinal motility and blood pressure. J Ethnopharmacol; 22: 111-116

Vichai V and Kirtikara K (2006) Sulforhodamine B colorimetric assay for cytotoxicity screening. Nat Protoc; 1: 1112-1116.

Wang J and Mazza G (2002) Effects of anthocyanins and other phenolic compounds on the production of tumor necrosis factor-in LPS/IFNactivated RAW 264.7 macrophages. J Agric Food Chem; 50: 4183- 4189.

Western AR (1989) Rhazya stricta Decne. In the Flora of the United Arab Emirates, an Introduction. United Arab Emirates Univ Press: Al-Ain; 111.

Yazdanparast R, Esmaeili MA and Ashrafi J (2005). Teucriumpolium extract effects pancreatic function of streptozotocin diabetic rats: A histopathological examination. Iran Biomed J; 9(2): 81-85.

Zhishen J, Mengcheng T and Jianmin GW (1999) The determination of flavonoid contents in mulberry and their scavenging effects on superoxide radicals. Food Chem; 64: 555-559. 